http://dx.doi.org/10.12795/PH.1989.v04.i01.34

\title{
EL INDIGENISMO NARRATIVO EN EL PARAGUAY
}

Augusto Roa Bastos

1. Debo comenzar por decir que tal corriente literaria no ha existido en ed Paraguay. Al menos en las formas con que se manifestaron en otras literaturas de Hispanoamérica, desde los balbuceos de cierto indianismo precursor, hasta los que podríamos considerar los autores, ya clásicos, del neoindigenismo en el curso del presente siglo: José María Arguedas, Ciro Alegría, Enrique López Albújar, en el Perú; Miguel Angel Asturias, en Guatemala; Jorge !caza, Demetrio Aguilera Malta, en el Ecuador, Gregario López y Fuentes, en México, o Alcides Arguedas en Bolivia. Menciono sólo a algunos de los narradores más representativos del género. Estos autores tomaron el tema del indio o del mundo indígena y crearon con sus novelas y cuentos un capítulo vigoroso en la literatura hispanoamericana.

Esta narrativa naciente no podía empezar sino siendo realista; hay que decirlo, en los modos más tópicos del realismo, en su manera de enfocar la desmesura de la naturaleza, los rasgos más típicos del poblador mestizo o indio, sus costumbres y modalidades regionales, los antiguos y profundos conflictos que separan y enfrentan, aun hoy, a estos sectores humanos en una lucha encarnizada y permanente. Gradualmente, esta visión realista, forzosamente exterior de los comienzos, fue profundizando en la materia raiga! que nutría sus intuiciones y temas y fue enriqueciéndose interiormente, compenetrada con la cosmovisión mítica de los portadores de las culturas antiguas. Las obras del guatemalteco Miguel Asturias y del peruano José María Arguedas, cada uno a su modo, desde ángulos diferentes y con procedimientos literarios distintos, podrían ser consideradas como paradigmas de esta evolución y afinamiento. El indigenismo narrativo se incorporó, de este modo, con títulos propios, a la novelística de las primeras décadas del siglo que estaba produciendo esas «novelas ejemplares», de las que habló un crítico e historiador de la literatura. El neoindigenismo aportó, así, una contribución de radical importancia a la producción literaria que surgía del mestizaje cu!- 
tural; importancia que acaso no ha sido valorada aún en todos sus alcances como un hito significativo en la historia de las literaturas regionales o nacionales hispanoamericanas.

\section{Replanteamiento necesario.}

Creo oportuno este replanteamiento del indigenismo narrativo en coordenadas más amplias y globalizadoras como una manera de depurarlo de las limitaciones reduccionistas que la crisis del realismo, por una parte, y el avance y explosión de la llamada nueva novela, de carácter predominantemente urbano, han tendido a situarlo como un subgénero o, en todo caso, como un anexo complementario de lo que se ha dado en llamar regionalismo literario. Tampoco es ajeno a esta desvalorización - que llega incluso al extremo de considerarlo como un género perimido-, el proceso de rápida y desorganizada transformación, tecnificación y crecimiento en la mayor parte de los países que se consideran «paises en vías de desarrollo» y que se hallan en realidad bajo el signo de la dependencia económica y del tremendo desorden que ella genera. En este contexto el mundo indígena ha quedado subsumido y como olvidado en medio de las grandes masas de desheredados y condenados de la tierra. Pero ésta es otra historia que desborda nuestro temario y exige otro tratamiento en un marco diferente del que nos ocupa, más propio de la etnohistoria y de la sociología, que de la historia literaria.

De todos modos, el problema es más complejo de lo que permiten suponer, a primera vista, las posturas reduccionistas en torno al indigenismo. Se trata ciertamente de un indigenismo narrativo, expresado en lengua castellana, cuyo módulo específico constituye la denuncia testimonial y reivindicativa del drama histórico y social de marginalización y etnocidio que hasta hoy padecen en América hispánica los grupos indígenas sobrevivientes. Narrativa Indigenista, sí, puesto que en tales condiciones no podía surgir una literatura indígena, propiamente dicha. Las lenguas y culturas vernáculas quedaron detenidas en un momento de su evolución y fueron desnaturalizándose a partir del largo proceso de la conquista y colonización y aun del mestizaje, que resultó todavía más duro y desintegrador bajo la férula del gamonalismo criollo o mestizo. Capítulo en el que habría que incluir también el drama del negro procedente de la esclavitud y de los inmigrantes asiáticos que arribaron a América en las primeras décadas del siglo.

En este contexto, y limitándose específicametne al indio, la ideología de superioridad del blanco o mestizo como explotador y opresor, reaccionó sin embargo positiva y humanamente en la conciencia de sus escritores y poetas, muchos de los cuales (como también había acontecido durante la conquista y colonización) defendieron la causa del indio en sus narraciones y poemas. En el proceso de transculturación, que fue el fenómeno predominante del mestizaje étnico y cultural, el indigenismo narrativo se constituyó así en una etapa fundacional de la literatura hispanoamericana, en forma más o menos análoga a lo que ocurrió con la presencia del negro en la literatura norteamericana. 
El indigenismo narrativo merece, pues, la corrección de los enfoques reductores y anacrónicos con criterios más modernos y actualizados de la crítica y de la historiografía literaria. En este sentido, la definición misma de indigenismo o indigenista trasciende la mera adjetivación de forma o género marginal, para adquirir su significación genuinamente literaria y creativa. Por otra parte, su función como tentativa de rescate y revaloración ética y social de esos sectores humanos condenados a ghettos mudos y errantes, despojados de sus tierras de origen, de sus lenguas y culturas ancestrales y condenados a una lenta extinción, no ha sido óbice para el logro de una gran calidad literaria en las obras más logradas del género.

Podría decirse, incluso, que ese barro sedimentario y oscuro del que surgió el indigenismo narrativo ha sido el semillero, mítico y realista a la vez, de la novela adulta de nuestros días. El novelista y cuentista peruano José María Arguedas es, probablemente, quien consubstanciándose e identificándose plenamente con la cultura viviente de su pueblo indígena llevó a su más alto nivel de plenitud ética y estética la fusión de las dos culturas, de las dos lenguas, de los dos mundos, que conviven en el drama de la expresión americana. Y lo hizo en un español terso y puro, de vertiginosa plasticidad y transparencia; un lenguaje de pasión y de lucidez como veteado de un halo de sangre y de sombra, de esa neblina primordial que flota en los cantos de las antiguas culturas. Al leer y oír a Arguedas en sus novelas y cuentos, al oír su voz individual en la que se agitan vastas pululaciones de pueblo, es imposible no escuchar también la voz poética de César Vallejo que viene de aquellos mismos hontanares y que logró en sus poemas, de modo definitivo en nuestro siglo, la transfusión de lo indígena y lo español: su transfiguración en una lengua nueva que no alteraba sino que enriquecía en profundidad la naturaleza de ambas.

De todo esto está hecho el indigenismo narrativo y poético con el que vida y escritura, naturaleza, historia y sociedad tomaron conciencia, por primera vez en la América hispánica, de su identidad de base, y enseñaron que las culturas no se excluyen sino que se integran en una continua metamorfosis.

\section{Una literatura ausente.}

La inexistencia de una narrativa indigenista en el Paraguay resulta un fenómeno tanto más curioso cuando se considera que este país es el único totalmente bilingüe en Hispanoamérica. La lengua de origen indígena es el verdadero idioma nacional y popular de carácter oral (puesto que el guaraní no llegó a la escritura), sobre un $95 \%$ de la totalidad de la población frente al castellano o español, que es la lengua oficial, la lengua de escritura, la lengua literaria. Pese a la presencia viviente del idioma indígena, que se hispanizó paulatinamente en la misma proporción en que guaranizó el castellano, el indigenismo narrativo no prosperó en Paraguay, como sucedió en Perú, Ecuador, Bolivia, Guatemala, México y otros países. El indio y el mundo indígena han quedado relegados en el Paraguay, casi exclusivamente, a la literatura etnográfica. 
Esto es lo que hace completamente atípico, y hasta contradictoria y paradójica, la inexistencia del indigenismo narrativo en el Paraguay en ninguna de sus formas escritas en lengua castellana. Tampoco aparece el indio - lo que es más extraño aún- en los sectores del folklore rural cuya oralidad sólo se da en guaraní, o sólo aparece como un ente fantasmal, y desfigurado por el rechazo del mestizo que descarga en el indio sus pulsiones de culpa, de su media sangre traidora. Aunque, por otra parte, se jacte de su ascendencia indígena, lo que hace aún más aberrante este sentimiento de retaliación y de desprecio.

Es casi obvio que la inexistencia del indigenismo narrativo en Paraguay se debe, entre otras causas, al atraso y a la ausencia misma de una literatura narrativa como un cuerpo de obras ligadas por denominadores comunes. Esta literatura ausente se debe, a su vez, a otras causas, como luego veremos. El atraso o ausencia de la narrativa paraguaya, como parte de una literatura nacional, se define por características de marginalización y asincronía en el contexto de la literatura hispanoamericana. Esta situación plantea por muchas razones - no sólo de orden material y cultural - una problemática diferente de las de los demás países; una problemática que permanece aún inexplorada en muchos aspectos, principalmente en los de orden histórico y socio-lingüístico.

\section{El bilingüismo y la cultura oral.}

Por lo pronto, el Paraguay presenta en América — como ya se ha dichoel único caso de un país totalmente bilingüe (quizás más correcto sería decir dilingüe). Tal como lo definió el sociolingüista norteamericano Joshua A. Fishman: «El bilingüismo en el Paraguay es el único patrón de bilingüismo a escala nacional en el mundo». El propio Fischman (1967) investigó la interacción entre bilingüismo (concepto elaborado por los psicólogos) y diglosia (concepto elaborado por los sociólogos. «Lo cierto - dice-que ni los lingüistas ni los sociólogos se habían dado cuenta, durante largo tiempo, de que lengua y sociedad revelan varios grados y modos de covariación estructurada («patterned co-variation»). Fischman delimita así, claramente, las dos situaciones de bilingüismo y diglosia: «El bilingüismo es esencialmente una caracterización del comportamiento lingüístico individual - dice-, en tanto que la diglosia es una caracterización de la organización lingüística en el plano socio-cultural».

Sin entrar en conceptualizaciones técnicas que no se podrían desarrollar adecuadamente en el breve espacio de este trabajo, lo que se podría decir de paso es que en el Paraguay el fenómeno del bilingüismo se define por la coexistencia de una lengua con escritura, el español, y de otra oral, el guaraní. En la práctica, la lengua de origen indígena es por excelencia el vehículo de comunicación nacional y popular. Esta lengua de origen y naturaleza oral -la civilización guaranítica que comenzaba a asentarse en un tardío neolítico cuando arribaron los españoles, no había entrado aún en la escritura- continúa teniendo un neto predominio de uso, sobre todo en el área rural. El lector paraguayo — no menos que el escritor- tiene muchas dificultades para adentrarse en la artificialidad de la es- 
critura y en los mecanismos de sugestión e ilusión de la ficciones, salvo que éstas vengan respaldadas por el prestigio de autoridad de los autores extranjeros de fama. Los lectores potenciales medios y masivos de la literatura escrita - proporcionalmente escasos en su conjunto- aceptan la vivacidad y la fantasía del relato oral en guaraní, pero rechazan la falta de verosimilitud «histórica y realista» - o la exigen en sus rasgos más gruesos - en el relato escrito en castellano. Desde el ángulo sociolingüístico, además, existe otra peculiaridad restrictiva: la que surge de una situación de conflicto entre estos dos universos lingüísticos en contacto y en fricción mutuamente erosiva (según el criterio de Uriel Weinreich, 1953). Esto ha producido el fenómeno, también recíproco, ya aludido, de la hispanización del guaraní y de la guaranización del idioma español, a tal punto que lingüistas y etnógrafos se han visto precisados a reclasificar el idioma formal y dominante como castellano-paraguayo y la lengua oral y dominaba como guaraní-paraguayo.

Con respecto a los campos semánticos sectoriales entre el castellano paraguayo y el guaraní paraguayo, es obvio que las mutaciones de la vida actual han ahondado cada vez más las diferencias que los separan. El discurso de lo rural y lo doméstico corresponde al ámbito del guaraní paraguayo. El universo inherente al castellano paraguayo corresponde a los usos de carácter formal, técnico y conceptual. A este universo pertenece la práctica de la literatura en el Paraguay, en sus diversos géneros y formas. En términos generales, puede decirse que el guaraní es la lengua que la madre indígena enseñó a sus hijos en las encomiendas de la colonia, y que el castellano es la lengua del padre, la lengua de poder y de mando que el conquistador y luego el colonizador impusieron a las sociedades nacientes.

Es evidente que el escritor bilingüe cuya lengua materna sea el guaraní y cuyas preocupaciones temáticas arraiguen en el mundo rural, podrá encarár con más felicidad y menos dificultades la elaboración de textos en guaraní cuya oralidad ha llegado ha expresarse, desde los tiempos de la Misiones jesuíticas, en la grafía de la lengua española enseñada por los misioneros y evangelizadores de la conquista espiritual. Distinta es la situación del escritor bilingüe cuya lengua materna es el castellano paraguayo. Su posibilidad de expresar el mundo rural en guaraní será desde luego mucho más limitada, en todo caso, más artificial. Pero hacerlo en castellano no le acarrea menos dificultades en la necesidad de trasponer, de «transculturar» el léxico, los significdos, prácticamente intraducibles, de este mundo confinado en el ámbito de la oralidad. Surgen entonces las inevitables traducciones literales entre paréntesis o al pie de páginas, las referencias y los vocabularios tan fastidiosos y anacrónicos en los textos de ficción.

\section{El vacío del pasado.}

En este cuadro forzosamente esquemático y volviendo al problema mayor de la cultura-paraguaya - la ausencia de un corpus de literatura narrativa- resalta un hecho a primera vista contradictorio: el que esta carencia exista precisa- 
mente en un país que, a mediados del siglo pasado, fue el más adelantado material y culturalmente de América del Sur, y a pesar de la riqueza de la experiencia histórica vivida por su pueblo. El Paraguay fue completamente arrasado y destruido en la larga guerra que una coalición de tres naciones hermanos llevó contra él entre 1865 y 1870. Tampoco es ésta la ocasión adecuada para hablar de aquel desastre nacional que determinó el atraso material, cultural y social de este pequeño país en su enclave mediterráneo; atraso del que no ha logrado reponerse por completo desde entonces y que impidió su resurgimiento.

La narrativa paraguaya no comienza sino a finales de la década de los años 40. Con un siglo de retraso, esta narrativa nace casi al mismo tiempo que la nueva novela latinoaméricana. Pero tal narrativa inaugural no es en el Paraguay sino una literatura sin pasado, en el sentido de una literatura carente de tradición, es decir, esta literatura sin pasado es la contatación de un pasado sin literatura. Este vacío impidió, por ejemplo, que llegaran a este país mediterráneo, encerrado en sus desgracias nacionales, oprimido por regímenes despóticos y oscurantistas, las corrientes culturales que habían transformado las ideas, las artes, las literaturas latinoamericanas. Al Paraguay no entraron sino muy tardíamente las influencias transformadoras del romanticismo o del modernismo. Tardarían aún más en llegar los ecos de las vanguardias europeas de entre las dos guerras mundiales, y no entraron por completo las influencias de la poderosa corriente de la literatura norteamericana de los años 20 , que se halla en la raíz de la transformación de las literaturas latinoamericanas.

Preocupados los escritores, novelistas e intelectuales paraguayos por la «omnubilación en marcha» de la historia patria, se desentendieron de la literatura de ficción novelesca que fue reemplazada totalmente por la producción monográfica de una seudo historiografía - la «guerra de cien años» de los folletos- en la que cada uno de los millares de improvisados y alucinados cronistas trataron de explicar con apasionado fanatismo faccioso aquellos enigmas de la «atástrofe de recuerdos». En esta barbarie colectiva el indio no existía sino como un salvaje, digno de exterminio o, en el mejor de los casos, de total abandono.

Esta folletería parásita, crecida y detenida en el pasado, al servicio de los mandones de turno, sofocó toda tentativa de crear textos libres e imaginativos en el nivel y con la densidad de los que se estaban produciendo en el resto de América. Menos aún, por supuesto, una literatura indigenista, salvo cierta tentativas ornamentales y vacías del mundo indígena que había dado a los paraguayos — según estos improvisados cronistas - la raza y la lengua en idílico connubio con los dioses blancos que habían traído el trueno, el caballo y la enfermedad mística del pálido Cristo. Una literatura, en fin, en la que se mezclaban todos los excesos y las falsedades de una voluntariosa «restauración» de la cultura indígena, agravada, además, por el hecho de constituir verdaderos adefesios literarios. Hubo que esperar mucho tiempo para que esta visión deformante del indio y de la cultura indígena fuera rectificada y restituida a sus genuinos valores por estudiosos verdaderamente capacitados como fue, entre otros, León Cadogan, fundador de la etnografía paraguaya. 


\section{Dos lenguas sin literatura.}

Sobre este transtorno acaso se revelen mejor algunas de las causas que han hecho hasta hoy de la literatura paraguaya una literatura ausente. En el inevitable proceso de evolución de toda lengua en situaciones históricas determinadas, la lengua originaria mantiene aún cierto grado de coherencia idiomática en los grupos tribales en que la etnia guaraní se halla dispersa sobre la tierra de sus antepasados. Sus hablantes sufren relegamiento y marginación en áreas de «reserva» que son verdaderos campos de concentración; o sometidos al trabajo esclavo en análogas o aun peores condiciones que los campesinos sin tierras, forzados a desalojos compulsivos, a persecuciones y vejámenes que configuran el largo y sistemático etnocidio del cual se ha hablado. Los cada vez más escasos sobrevivientes guaraníes, al igual que los componentes de las demás etnias de las dos regiones del país (Oriental y Occidental o Gran Chaco), padecen la prolongada agonía de su destrucción biológica y desintegración cultural.

Sobre este fondo sombrío de dos colectividades que integran un país pero que se rechazan mutuamente, pese a enfrentar el mismo drama de desintegración cultural y social, la suerte de la colectividad indígena es desde luego la más castigada. Para los portadores de la palabra primigenia, el porvenir no cuenta ya sino como acabamiento definitivo. Acorraladas y acosadas en sus mismos fundamentos culturales, materiales y biológicos, perdura sin embargo en ellas la radiación de sus núcleos indisolubles, la unidad y originalidad de una cosmovisión identificada aún con sus modos de ser y de vivir su propia identidad. Su lenguaje ha recuperado entonces su carácter sagrado en el que la palabra profética y mesiánica anunciaba el fin último pero también la salvación. Sus cantos rituales, las antiguas hermosas palabras expresan la aspiración de alcanzar un más allá de la muerte; de sobrevivir a ese porvenir que sólo puede anticiparse para ellos bajo la forma de un peligro absoluto.

Este lenguaje cosmogónico estructurado en símbolos y en mitos impregnados aún del animismo primordial, desborda el tiempo, al menos en la dimensión antropocéntrica que marca las características pero también los límites de las expresiones y manifestaciones de la cultura blanca. El lenguaje de las culturas indígenas entraña un sentido que anula nuestros conceptos de temporalidad y especialidad. Forma constelaciones míticas en las cuales el sentido de permanencia funciona no como una vuelta regresiva al pasado sino como una totalidad del tiempo y de la memoria. Totalidad en la que pasado y futuro confluyen en la dimensión de la palabra sagrada.

Tal coherencia ha sido quebrada de pronto - tal vez desde hace siglos - por la irrupción del sentimiento del fin último, de ese porvenir que se da para sus componentes no ya como el horizonte mítico de una sobrevivencia posible, sino como la forma de ese peligro absoluto que ya no es la muerte física sino algo mucho peor: la imposibilidad de llegar a la tierra virgen y sin mal: el Yvy-marane'y de los antiguos guaraníes. Aquella utopía sobrenatural de los antepasados se expresa en uno de los cantos del Himno de los Muertos en que habla el Gran Padre Último-Último-Primero: 
«... He de hacer que la voz vuelva a fluir por los huesos...

Y haré que vuelva a encarnarse el habla...

Cuando se pierda este tiempo y un nuevo tiempo amanezca...»

La oposición entre lo «dicho» en los cantos orales y corales y lo «escrito» en las letras paraguayas, señala un distingo que considero significativo: el que va de lo vivo del acervo oral, del pensamiento colectivo en continuo movimiento de invención, a lo fijado en los textos de escritura letrada, de carácter siempre individual. Lo oral se genera y recrea a sí mismo sin cesar sobre módulos genuinos, no desarticulados todavía por elementos extraños a su propia identidad y autenticidad. A propósito del tema de la oralidad y la escritura quisiera citar un bello y profundo texto de Juan Rulfo quien hizo esta profesión de fe, ejemplar y ejemplarizadora: "Quería no hablar como se escribe, sino escribir como se habla; el que habla relata al que oye sus propios movimientos. Lo que hago es una trasposición literaria de los hechos de mi propia conciencia. La trasposición no es una deformación sino el descubrimiento de formas especiales de sensibilidad. No es una cuestión de palabras. Siempre sobran, en realidad. El dolor es doloroso para cualquiera. Lo que pasa es que en el coro de todas las voces universales y gloriosas yo volví a oír la voz profunda y oscura».

Lo escrito en lengua «culta» en sociedades dependientes y atrasadas, como es el caso doloroso del Paraguay, distorsiona las modulaciones del genio colectivo. Y esto continuará sucediendo mientras los modelos y las normas venidos de fuera no sean asimilados por el proceso de transculturación, que a su vez debe ser sobrepasado y asimilado en formas auténticas de expresión en la interioridad de una cultura. Por fértil y constructiva que sea una idea venida de fuera no arraigará ni se aclimatará en un país de cultura en formación, mientras la propia vida nacional no consiga hacer surgir de sí misma esa idea de una manera natural como una necesidad sentida y reconocida por todos.

\section{Mito y naturaleza.}

En la base y en el ápice de este fenómeno domina la necesidad de la presencia del mito que consiste — según lo expresó acertadamente Roland Barthes, desde la cosmovisión de una cultura central- «en convertir la cultura en naturaleza, o al menos en convertir lo social, lo cultural y lo ideológico, lo histórico, en hechos naturales puesto que lo que el mito restituye, en el contexto de una cultura, es una imagen natural de lo real».

En cierto modo, esto es lo que ocurrió en la corriente del indigenismo literario. Esto falta en la literatura paraguaya, ausente ella misma por las razones anotadas y otras muchas que desbordan la simple racionalidad con que se enfocan los fenómenos culturales. Estos «hechos naturales» que el mito restituye en el contexto de una cultura se encuentran, en cambio, con una radiación inagotable en la tradición oral de la cultura paraguaya, indígena y popular. Los escritores paraguayos, inmersos en el exilio interior de una cultura dependiente y atrasada, bajo el signo implacable de la represión, o dispersos por el mundo en el alejamiento 
voluntario o forzoso del exilio exterior, conocen y sienten el vigor vital que se desprende de esta cultura oral en la que palpita la «voz profunda y oscura». Saben ahora con meridiana claridad que una obra literaria vale no por su refinamiento formal y esteticista solamente, ni por las ideas y opiniones proclamadas por su autor en la forma más primaria y superficial del dogma del «compromiso». Saben que una obra literaria, que una obra artística en general, vale por la verdad de las representaciones que irradia al ser concebida y construida sobre el foco de energía social y bajo la ley del tiempo que a estos autores les toca vivir y expresar. Y saben, sobre todo, que ello sólo puede acontecer cuando el autor la construye sobre el eje de su libertad íntima y última. Este juego o conjugación de la energía social con la libertad individual es lo que hace que los fenómenos de transculturación — que es el mérito mayor del indigenismo literario- obtengan su necesidad equilibrio y se conviertan en elementos de genuina transformación de una sociedad y de sus auténticos valores culturales. Sólo así - como lo quisieron y lo practicaron esos escritores que se inclinaron a escuchar y auscultar el corazón de sus pueblos- podrán lograr que entre el coro de todas las voces universales y gloriosas vuelva a oírse la voz profunda y oscura. 